\title{
Hyposplenism, antiendomysial antibodies and lymphocytic colitis in collagenous sprue
}

\author{
Hugh J Freeman MD
}

HJ Freeman. Hyposplenism, antiendomysial antibodies and lymphocytic colitis in collagenous sprue. Can J Gastroenterol 1999;13(4):347-350. A 66-year-old woman was seen repeatedly over a decade to remove recurrent colonic adenomas and investigate episodes of watery diarrhea. Although the diarrhea was believed to be due to lymphocytic colitis, she developed weight loss, hypoproteinemia and hyposplenism that resulted in further studies, specifically to exclude celiac disease. Small intestinal biopsies, however, showed severely 'flattened' villous architecture with trichrome-positive subepithelial collagenous deposits, characteristic of collagenous sprue. Antiendomysial antibodies, known serological markers of celiac disease, were also detected. While collagenous sprue has been considered a distinct small intestinal disorder, the constellation of clinical and pathological findings in this patient suggests a close link with adult celiac disease.
Key Words: Celiac disease; Collagenous sprue; Diarrhea

viously observed in 1947 (2). By 1980, at least 10 patients had been described (3-15), all with similar clinical and pathological features - significant malabsorption, 'flattened' small intestinal villous architecture and distinctive subepithelial collagen deposits. To date, convincing evidence for histological improvement in response to different therapeutic modalities has not become available, in part because the distribution and severity of the pathological lesion are so variable (16).

The precise relationship of collagenous sprue to celiac

Department of Medicine (Gastroenterology), University of British Columbia, Vancouver, British Columbia

Correspondence and reprints: Dr Hugh Freeman, ACU F-137, Gastroenterology, Vancouver Hospital (UBC site), 2211 Wesbrook Mall, Vancouver, British Columbia V6T 1W5. Telephone 604-822-7216, fax 604-822-7236

Received for publication January 5, 1999. Accepted February 19, 1999 


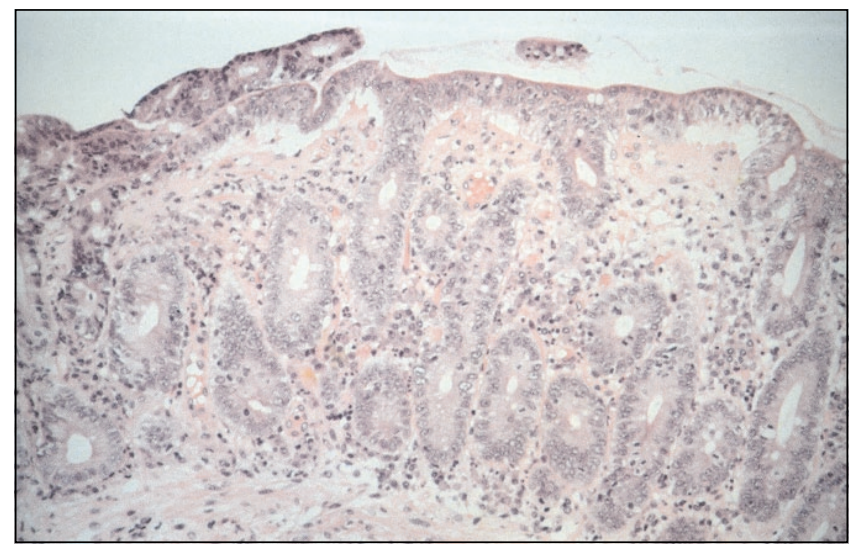

Figure 1) Small intestinal biopsy stained with hematoxylin and eosin showing severe 'flat' lesion with subepithelial eosinophilic hyaline deposits in the lamina propria, typical of collagenous sprue

disease also remains quite controversial. Some have viewed collagenous sprue as a distinct small bowel disorder, while others have suggested that collagen deposition in the small bowel mucosa of patients with celiac disease is a specific morphological marker of a poor prognosis (17. 19).

The present report describes a patient with recurrent episodes of watery diarrhea, initially attributed to lymphocytic colitis, a condition previously seen in celiac disease (20). In addition, weight loss and hypoproteinemia developed, and hyposplenism was later detected, which has also been described in celiac disease $(21)$ as well as in small bowel lymphoma complicating celiac disease (22). Finally, antiendomysial antibodies, serological markers of adult celiac disease (23), were also detected. Biopsies of her small intestine, however, showed a rare mucosal disorder, collagenous sprue.

\section{CASE PRESENTATION}

A 66-year-old woman was initially evaluated in January 1985 for watery diarrhea. Fecal samples were negative for bacterial pathogens and parasites. Results of barium radiographic studies of the upper and lower gastrointestinal tract were normal. Colonoscopic biopsies revealed lymphocytic colitis and an incidental $2 \mathrm{~cm}$ tubulovillous adenoma with focal severe dysplasia that was treated with excisional snare polypectomy. Results of other investigations, including a hemogram, red blood cell folate, serum carotene, vitamin B12, iron and iron-binding capacity, and serum proteins with albumin, were normal. Serum levothyroxine level was normal. She was re-evaluated for diarrhea in 1986. Another dysplastic adenoma was removed, and further fecal samples were negative for bacterial pathogens and parasites. Laboratory blood test results were normal. In 1987, another adenomatous polyp was resected, and fecal cultures revealed Yersinia enterocolitica, biotype 1 , serotype 6,30 . Specific treatment was not prescribed, and repeat fecal cultures were negative. Her diarrhea spontaneously resolved. In 1988 and 1989, results of additional colonoscopic evaluations were normal; no new

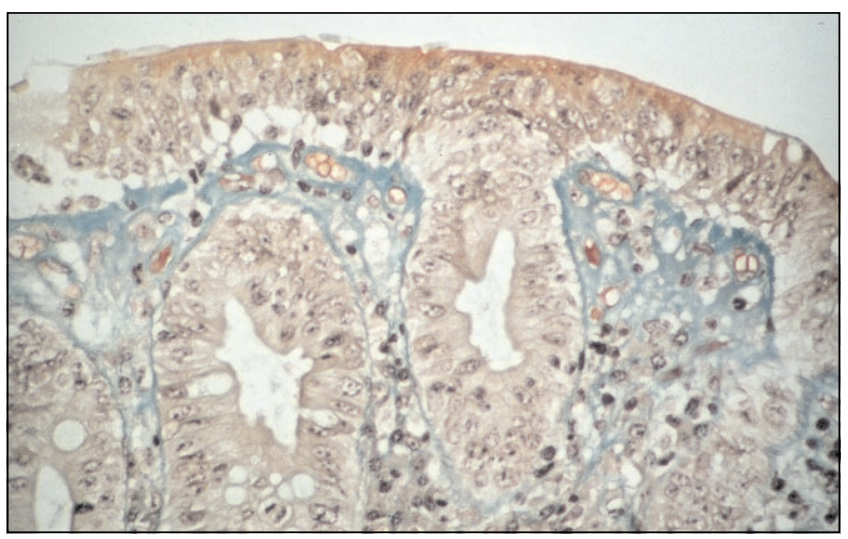

Figure 2) Same biopsy as in Figure 1stained with trichrome and showing the blue coloured subepithelial collagenous material in the lamina propria region

polyps were detected and the colonic mucosa was normal on biopsy. In 1991, a severely dysplastic adenomatous polyp was resected from the cecum, but the results of another colonoscopic evaluation in 1992 were normal. Diarrhea recurred in 1993. Fecal samples were negative for bacterial pathogens and parasites. A colonoscopy showed lymphocytic colitis on biopsies but no polyps. In 1994 and 1995, colonoscopic excisions of sessile dysplastic tubular adenomas from the cecum and descending colon, respectively, were required, and her diarrhea spontaneously resolved. In 1996 and 1997, results of further colonoscopic evaluations were negative and the colonic mucosa was normal on biopsy.

In May 1998, watery diarrhea recurred and weight loss developed. The results of a flexible sigmoidoscopy and rectal biopsy were normal. Laboratory study results, including a hemogram, international normalized ratio, blood urea nitrogen, serum creatinine, electrolytes, calcium, phosphate, liver chemistry tests (aspartate aminotransferase, alanine aminotransferase, alkaline phosphatase), immunoglobulins, serum thyroid-stimulating hormone, red cell folic acid, serum vitamin B12, serum iron and iron binding capacity, were normal, but her serum albumin level was reduced to $29 \mathrm{~g} / \mathrm{L}$ (normal 35 to $50 \mathrm{~g} / \mathrm{L}$ ). The upper gastrointestinal tract was normal on endoscopy, and her stomach was normal on biopsy, with no evidence of lymphocytic (24) or collagenous gastritis (25); however, endoscopic mucosal biopsies of her duodenum (Figure 1) revealed a severe 'flat' small intestinal biopsy lesion, with the typical subepithelial deposits of collagenous sprue (1). A trichrome stain of these subepithelial deposits for collagen was also positive (Figure 2). Because of the 'flattened' biopsy appearance and resemblance to the histological features of celiac disease, a gluten-free diet was initiated. By October 1998, her weight had increased by $5 \mathrm{~kg}$, but endoscopic biopsies revealed no convincing evidence of histological improvement with persistence of the subepithelial collagenous deposits. Results of repeated laboratory studies, however, were normal except for her peripheral blood smear, which showed evidence of splenic hypofunction 


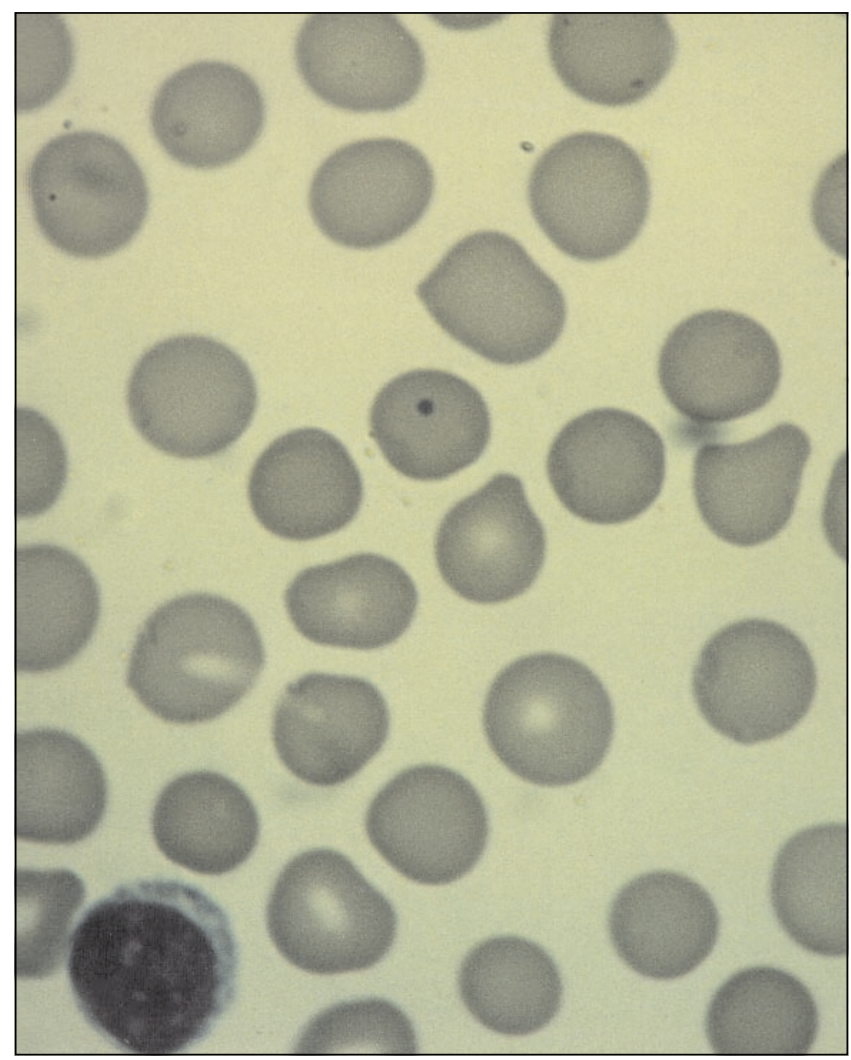

Figure 3) Peripheral blood smear showing classical features of hyposplenism with Howell-Jolly bodies

with Howell-Jolly bodies (Figure 3), which are often detected with celiac disease. Finally, antiendomysial antibodies were detected by using human umbilical cord as a substrate (Figure 4).

Further historical data revealed that the patient was born in Canada and had no known family history of celiac disease. She had no prior history to suggest an extraintestinal manifestation of celiac disease, including dermatitis herpetiformis.

\section{DISCUSSION}

Collagenous sprue is a rare disorder of the small intestinal mucosa that was initially described in a patient thought to have celiac disease with severe malabsorption (1). In spite of a gluten-free diet, the disease persisted with refractory malabsorption. Although cases of collagenous sprue have only been rarely reported, the precise relationship to celiac disease remains controversial. Some believe that the presence of pathologically significant deposits of collagen in the lamina propria may be a marker of a poor prognosis in patients with celiac disease, especially if these are extensively present throughout the length of the small intestine. Others believe that collagenous sprue is a truly distinct clinical and pathological entity, entirely separate from celiac disease.

In the present patient, episodes of watery diarrhea were present for over a decade, and these were attributed to the 'newly' described entity of lymphocytic colitis. This form

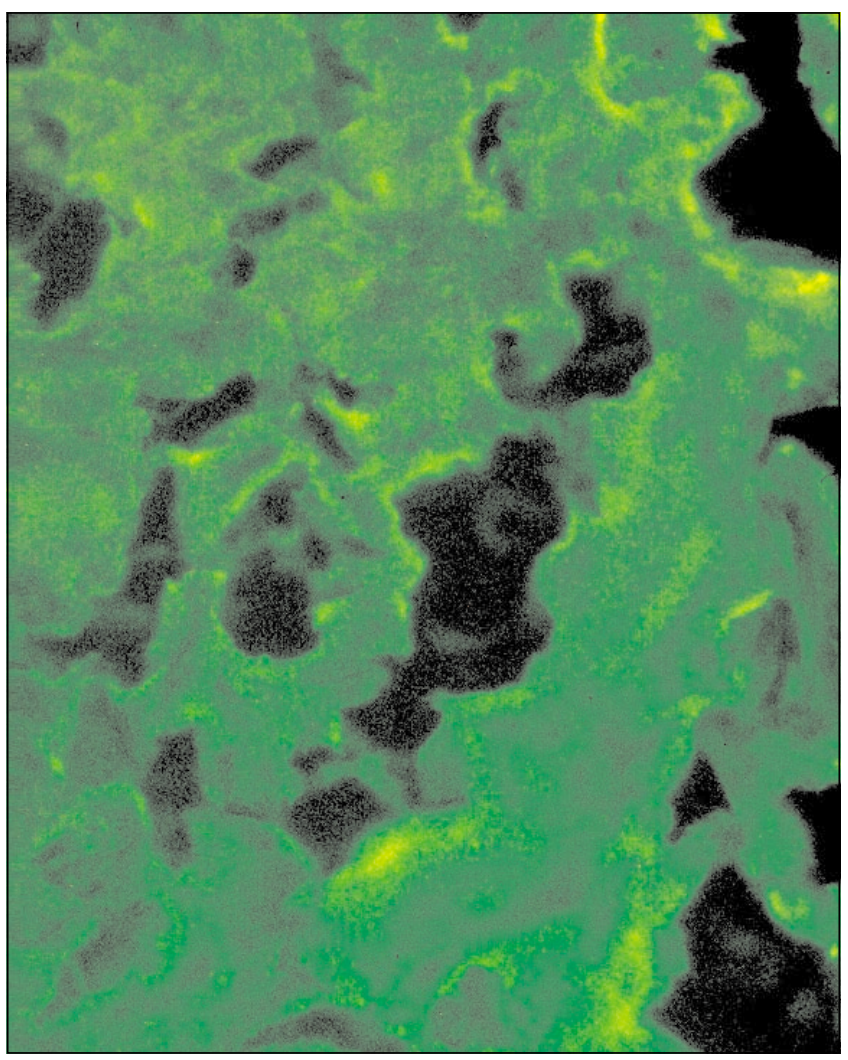

Figure 4) Positive test for endomysial immunoglobulin G antibody using human umbilical cord

of microscopic colitis has been previously associated with celiac disease (20), as has collagenous colitis (26), another more commonly detected collagenous inflammatory mucosal disorder (16). Although there are no prospective data available to determine the precise frequency of these differing forms of microscopic colitis in celiac disease, collagenous involvement of the small and large intestinal mucosa has been previously noted in at least one patient (27), and collagenous gastritis (25) has been seen in a patient with lymphocytic colitis (28). The relationship presented here, however, of lymphocytic colitis and collagenous sprue is novel.

In all previous reports of collagenous sprue, functional hyposplenism or seromarkers, specifically antigliadin or antiendomysial antibodies, characteristic of celiac disease, were not detected. Thus, their detection in this patient with collagenous sprue is not only unique but also provides additional evidence, albeit indirect, that these apparently separate and histologically distinct small intestinal mucosal disorders may be closely linked.

ACKNOWLEDGEMENT: The author is grateful to Dr Helen R Gillett for performing the antiendomysial antibody testing in this patient.

\section{REFERENCES}

1. Weinstein WM, Saunders DR, Tytgat GN, Rubin CE. Collagenous 
sprue. An unrecognized type of malabsorption. N Engl J Med 1970;283:1297-301.

2. Schein J. Syndrome of nontropical sprue with hitherto undescribed lesions of the intestine. Gastroenterology 1947;8:438-60.

3. Hourihane DO. The histology of intestinal biopsies. Proc R Soc Med 1963;56:1073-7.

4. Hines HW, Aldersberg D. Pathologic studies in idiopathic sprue. J Mt Sinai Hosp NY 1957;24:251-72.

5. Barry RE, Morris JS, Read AE. A case of small intestinal mucosal atrophy. Gut 1970;11:743-7.

6. Barry RE, Morris JS, Read AE. Collagenous sprue. N Engl J Med 1971;284:1041.

7. Neale G. Clinicopathological conference. Case of adult coeliac disease resistant to treatment. Br Med J 1968;ii:678-84.

8. Booth $\mathrm{CC}$. The enterocyte in coeliac disease. Br Med J 1970;4:14-7.

9. Doe WF, Evans D, Hobbs JR, Booth CC. Coeliac disease, vasculitis, and cryoglobulinemia. Gut 1972;13:112-23.

10. Holdstock DJ, Oleesky S. Vasculitis in coeliac disease. Br Med J 1970;4:369.

11. Holdstock DJ, Oleesky S. Successful treatment of collagenous sprue with combination of prednisolone and gluten-free diet. Postgrad Med J 1973;49:664-7.

12. Sheehy TW, Staats OJ. Collagenous sprue. A case report. Ala J Med Sci 1972;9:392-6.

13. Dowling RH, Henry K. Clinicopathological conference.
16. Freeman HJ. Collagenous inflammatory mucosal diseases of the gastrointestinal tract. Can J Gastroenterol 1990;4:196-200.

17. Bossart R, Henry K, Both CC, Doe WF. Subepithelial collagen in intestinal malabsorption. Gut 1975;16:18-22.

18. Whitehead R. Mucosal Biopsy of the Gastrointestinal Tract. Major Problems in Pathology, vol 4. Philadelphia: WB Saunders, 1990:220-3.

19. Perera DR, Weinstein WM, Rubin CE. Small intestinal biopsy. Hum Pathol 1975;6:157-217.

20. Wolber R, Owen D, Freeman HJ. Colonic lymphocytosis in patients with celiac sprue. Hum Pathol 1990;21:1092-6.

21. O'Grady JG, Stevens FM, Harding B, O’Gorman TA, McNicholl $\mathrm{B}, \mathrm{McCarthy} \mathrm{CF}$. Hyposplenism and gluten sensitive enteropathy. Gastroenterology 1985;87:1326-31.

22. Freeman HJ, Chiu BK. Small bowel malignant lymphoma complicating celiac sprue and the mesenteric lymph node cavitation syndrome. Gastroenterology 1986;90:2008-112.

23. Gillett HR, Freeman HJ. Serological testing in screening for adult celiac disease. Can J Gastroenterol. (In press)

24. Wolber R, Owen D, Delbuono L, Appelman H, Freeman HJ. Lymphocytic gastritis in patients with celiac sprue or spruelike intestinal disease. Gastroenterology 1990;98:310-5.

25. Freeman HJ, Piercey JRA, Raine RJ. Collagenous gastritis. Can J Gastroenterol 1989;3:171-4.

26. Hamilton I, Sanders S, Hopwood D, Bouchier IA. Collagenous colitis associated with small intestinal villous atrophy. Gut
Non-responsive coeliac disease. Br Med J 1972;4:369.

14. Pepper HW, Brandborg LL, Shanser JD, Goldberg HI, Moss AA. Collagenous sprue. Am J Roentgenol Radium Ther Nucl Med 1974;121:275-82.

15. Zeman RK, Tomer RG. Collagenous sprue. Am J Gastroenterol $1978 ; 70: 541-4$.
1986;27:1394-8.

27. Eckstein RP, Dowsett JF, Riley JW. Collagenous enterocolitis: a case of collagenous colitis with involvement of the small intestine. Am J Gastroenterol 1988;83:767-71.

28. Groisman GM, Meyers S, Harpaz N. Collagenous gastritis associated with lymphocytic colitis. J Clin Gastroenterol 1996;22:134-7. 


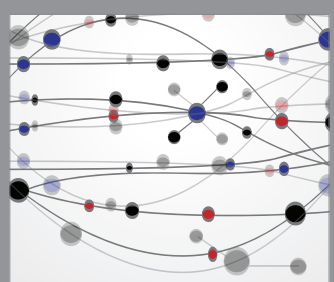

The Scientific World Journal
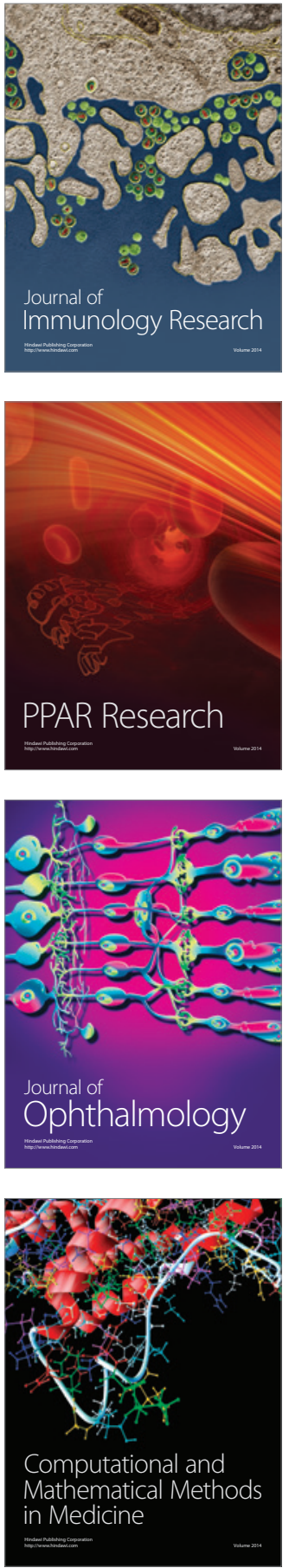

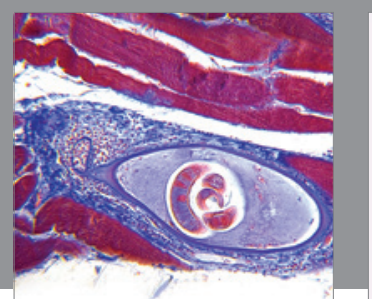

Gastroenterology Research and Practice

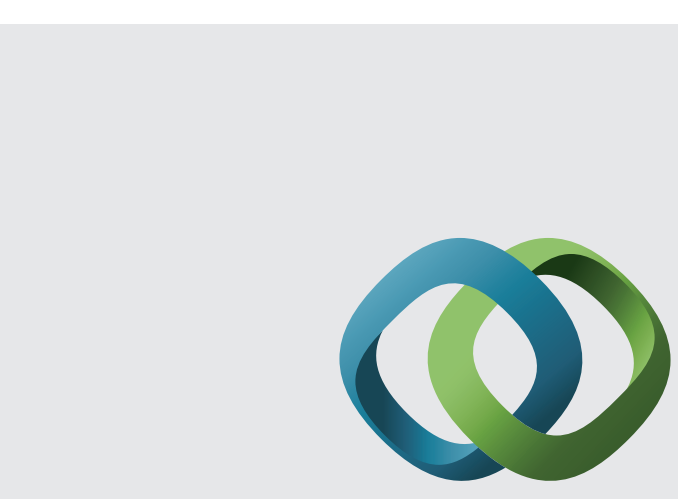

\section{Hindawi}

Submit your manuscripts at

http://www.hindawi.com
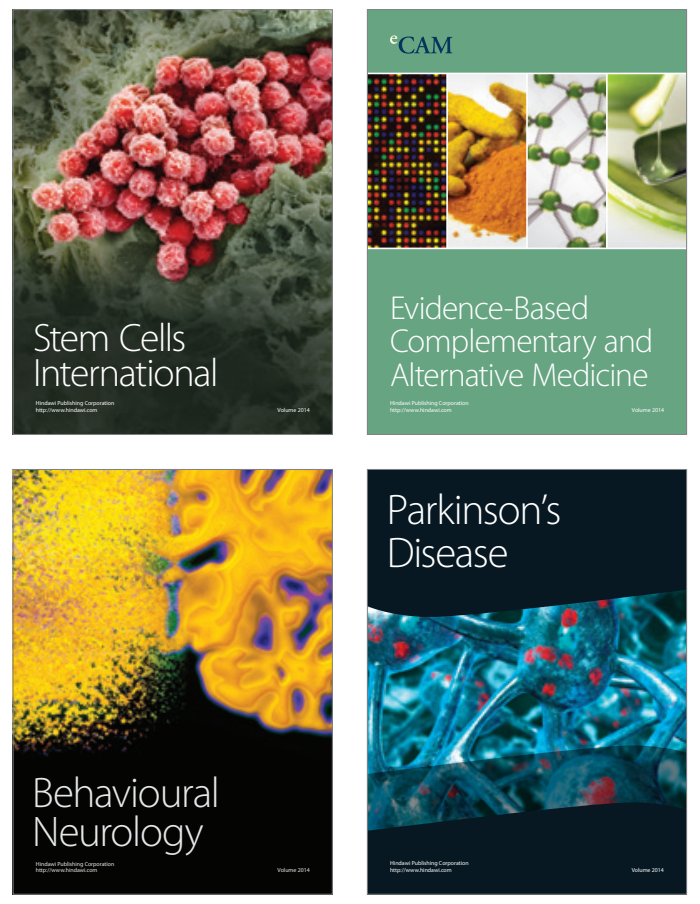
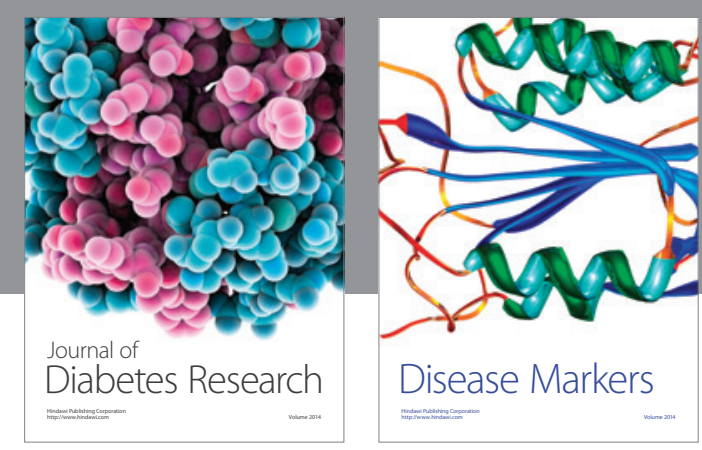

Disease Markers
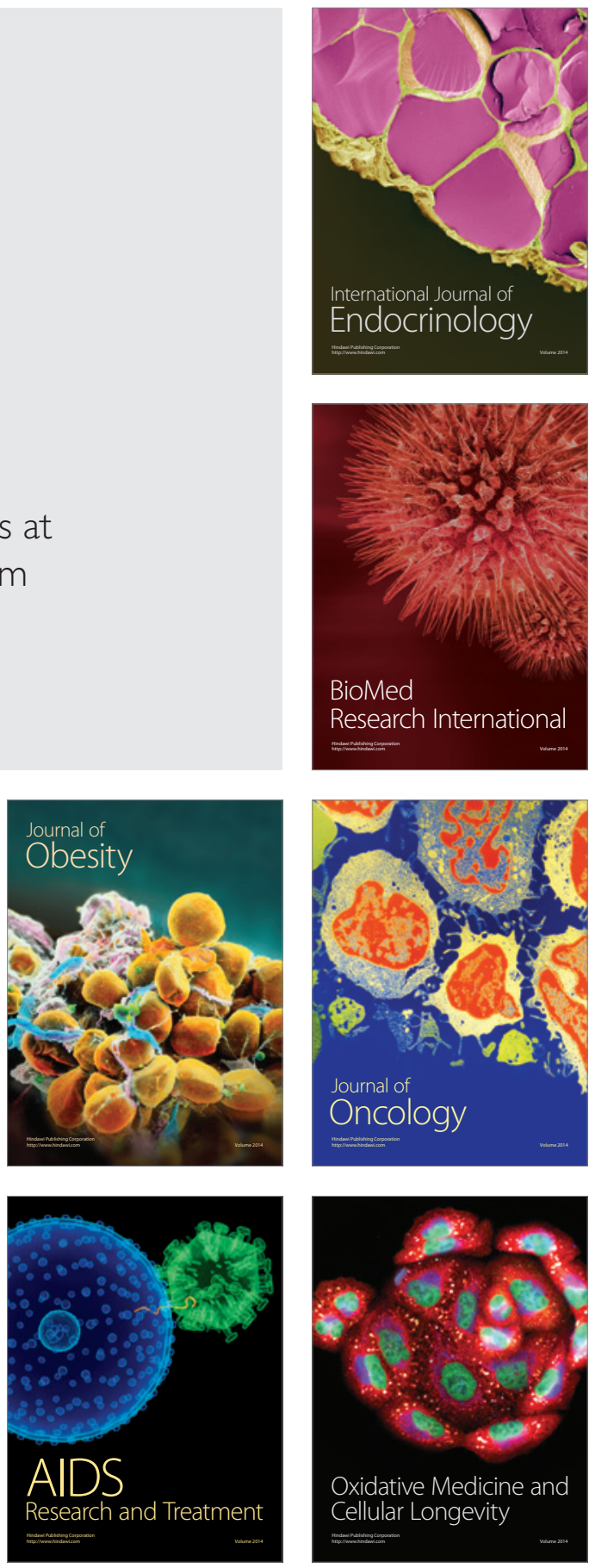